\title{
Grounded Theory in Medical Laboratory Science Expert Practice Development
}

\author{
ELIZABETH KENIMER LEIBACH
}

ABSTRACT

Grounded theory and methods related to expert practice development in medical laboratory science were described using data from a large national survey of medical laboratory scientists (MLS) overlaid on findings from analysis of expert practice domains reported in nursing literature. An extensive focus group/expert review iterative process followed by a survey of MLS practitioners produced 25 critical thinking (CT) behaviors important in expert practice. Factor analysis was applied to discern common threads or themes linking the CT behaviors. The 25 important CT behaviors were reduced to a 7-factor structure representing constructs underlying the individual, observable CT behaviors. This 7-factor structure in MLS was compared to the 7 practice domains identified in expert nursing practice. The comparison yielded commonality between MLS and nursing in CT behaviors observed in the 7 expert practice domains of both professions: professional techniques, caring communication, growing professionally, setting priorities, practicing with judgment, anticipating/revising, and creating unique meaning. Emergent grounded theory is that (1) critical thinking is a metaprocess that facilitates learning by interlinking the more basic processes associated with different learning orientations: cognitivist, behaviorist, humanist (affective), and situated/contextual learning, (2) CT behaviors are observable events following from the CT metaprocess, and (3) observations of CT behaviors increase as practice advances from novice to expert. Identification and definition of CT behaviors, i.e., practice competencies, along the continuum of novice to expert can serve as the foundation for MLS curriculum and instructional design as well as measurement and evaluation in both formal and continuing education settings.

ABBREVIATIONS: CLS or MLS - clinical (medical) laboratory science/clinical (medical) laboratory scientist; DCLS or DMLS - doctorate in clinical (medical) laboratory science; EBM - evidence-based medicine; EBLM - Evidence-based laboratory medicine; EBP evidence-based practice

INDEX TERMS: Critical thinking; evidence-based laboratory medicine; expert practice; grounded theory; instructional strategies

Clin Lab Sci 2011;24(4):Suppl 4-37

Elizabeth Kenimer Leibach, Ed.D., M.S., $M L S(A S C P)^{C M}, S B B^{C M}$, Centers for Disease Control and Prevention, Atlanta, GA

Address for Correspondence: Elizabeth Kenimer Leibach, Ed.D., M.S., MLS(ASCP) ${ }^{C M}, S B B^{C M}$, Senior Service Fellow, Evidence-based Laboratory Medicine Project Lead, Laboratory Research and Evaluation Branch, Division of Laboratory Science and Standards, Office of Surveillance, Epidemiology, and Laboratory Services, Centers for Disease Control and Prevention, 1600 Clifton Road, NE, Atlanta, GA 30329, eleibach@cdc.gov

\section{INTRODUCTION}

By many measures, the U.S. health care delivery system has been phenomenally successful. Our medical community has made unparalleled advances in diagnostic and therapeutic regimens, in biomedical research, and in the development and use of innovative technology. We enjoy unrivaled clinical and educational facilities. However, there is growing public recognition that some things are fundamentally wrong with the system and the health care it provides the citizens of the nation. The single most troubling issue in health care is the growing aggregate cost. We spend more on health care, in total and per capita, than any other nation in the world. ${ }^{1}$ And total health spending has reached upward of $17 \%$ of Gross Domestic Product (GDP), the highest proportion of health spending for any nation in the world. ${ }^{2}$ 


\section{RESEARCH AND REPORTS}

Two of the many avenues being explored to help reduce spiraling health care costs are to move health care delivery outside the expensive hospital arena and to curtail unnecessary or costly duplication of laboratory services. The profession of medical (clinical) laboratory science (MLS) is being radically reshaped by the convergence of these trends. Traditionally, members of this health profession are formally trained in associate or baccalaureate degree programs, practice in technically complex, highly computerized environments, and have little direct patient contact. One of the primary effects of the changing health care milieu is the increasing availability of user-friendly technology in diagnostic laboratory testing which can be successfully operated by persons not formally trained in medical laboratory science. Thus, more and more laboratory testing is being performed by people within the health care field other than medical laboratory science practitioners and even by consumers in the home testing market who are outside the health care professions altogether. The resultant patient information is being networked among health care delivery organizations and unnecessary, duplicative testing is being identified. There is an increased demand for practitioners who can process the rapidly expanding body of knowledge, validate appropriateness of diagnostic and therapeutic information, problem-solve, interact with and relate to persons with widely divergent interests and needs, meaningfully interpret the results of laboratory testing for patients and other healthcare practitioners, and route laboratory information to clients, other health care disciplines and consumers, as needed. ${ }^{3,4,5}$

\section{Critical Thinking in MLS Practice}

To meet the challenges of today's increasingly varied and complex workplace, practitioners must become thinkers who know a great deal and continually adapt and refine, while they use their knowledge. Basic psychomotor and associated cognitive skills are not enough in and of themselves. Success today requires new basics: the ability to reason, analyze, plan, and act effectively in a climate of change. ${ }^{6}$ This means practitioners of today must adjust for input that challenges their current thinking, and make appropriate, reasoned use of the understanding that develops. This process never ends.

Each new situation in which understanding is needed generates further information and insights, and these in turn may call for subtle or radical reconfiguration of a practitioner's knowledge structures. Such knowledge structures are fluid and constantly changing. This view suggests that even though knowledge may be accumulated and shared, knowing is personal and involves gaining closer and closer approximations of a sense of certainty. In this process, practitioners engage in a kind of dialogue with themselves, their environment, and others and constantly revisit the many issues and problems with which they are grappling. ${ }^{7}$ Practitioners are not recorders of information, but architects of knowledge structures. So, knowing is to have received and interpreted knowledge, and related that knowledge to other knowledge. And to be considered skilled, one not only can perform some task, but knows when to perform it and can adapt the performance to varied circumstances. ${ }^{8}$ This process involving the type of thinking through which knowledge is expanded by meaningful experience is critical thinking $(\mathrm{CT}){ }^{6}$

Critical thinking (CT) has been identified as foundational in the learning process. Different from unguided, random "thinking," CT is a much more active and directed function defined by consensus of Paul and other CT experts, as follows:

"Critical thinking is the intellectually disciplined process of actively and skillfully conceptualizing, applying, analyzing, synthesizing, and/or evaluating information gathered from, or generated by, observation, experience, reflection, reasoning, or communication, as a guide to belief and action. In its exemplary form, it is based on universal intellectual values that transcend subject matter divisions: clarity, accuracy, precision, consistency, relevance, sound evidence, good reasons, depth, breadth, and fairness."

This consensus definition was the culmination of much research elucidating the role of critical thinking in facilitating learning in all domains, i.e., cognitive, behavioral, affective, and situated/contextual. Critical thinking is not a learning theory, as such. According to Kenimer Leibach, CT is:

"more akin to a gestalt through which knowledge and experience (or abstract and practical knowledge, respectively), and the context (animate, inanimate, 


\section{RESEARCH AND REPORTS}

personal characteristics, and interpersonal/societal relationships) interact to produce new knowledge and actions which can be both individually and socially constructed." ${ }^{6,10}$

In her research in clinical (medical) laboratory science (CLS), Kenimer Leibach operationalized the definition of critical thinking as "a metaprocess that facilitates learning by interlinking the more basic processes associated with the different learning orientations: behaviorist, cognitivist, humanist, and situated/contextual learning." This work lead to the definition of CLS CT behaviors (skills) as "observable events following from the CT process," and the strong suggestion of homology of these behaviors with behaviors characteristically observed in expert practice. Implicit in these conclusions, also, is the understanding that CT does not occur in isolation, but is dependent on sufficient levels of discipline-specific knowledge with which to engage, e.g. analyze, synthesize, evaluate. , $^{610}$

Subsequently, Kenimer Leibach and Russell reported an educational typology, or instructional framework, for teaching research CT skills across all degree levels of the medical (clinical) laboratory science curriculum. ${ }^{11}$ The premise underlying the typology design comprises three primary assumptions: (1) CT behaviors, observable events following from the CT process, are exemplified in expert practice, (2) teaching these CT behaviors for expert practice requires sufficient levels of disciplinespecific knowledge and interaction with application contexts, and (3) CT behaviors in practice become more complex, involving more learning orientations of the CT metaprocess, with expanded practice roles associated with advanced degrees. The development of this typology articulates the final constructs necessary for emergence of education theory hypothesizing the relationship among elements of the cognitive CT metaprocess, observable CT behaviors, and the development of expert practice. The purpose of this research was to discover an empirically-based theory to explain the development of expert practice behaviors and to suggest instructional strategies and clinical research agenda, best aligned with theory, to support their pedagogy.

\section{METHODS FOR CT GROUNDED THEORY DEVELOPMENT IN CLS}

Why is theory and theory-building important? In its dis- tillation, theory is an association of broad, multifaceted concepts (called constructs) that organize observations from real life into useful frameworks that can be tested, through subsequent investigations, for validity, cohesion, and "goodness of fit." Theory is useful if its supporting constructs can be teased apart into measureable components. ${ }^{12}$ If so, then theory provides the description of relationships necessary to structure formal inquiry. Most theory in MLS is deductive, that is, theory that is inferred from hypothesis-testing. In contrast, grounded theory is an inductive approach to research that focuses on contextual observations and interviews to build theory from data rather than to test deductive theory by description of or inference from empirical phenomena. ${ }^{12,13}$ Following is a description of methods employed in discovery of grounded theory explaining expert practice development in medical laboratory science.

Kenimer Leibach reported the identification of 65 CT behaviors observed in CLS (MLS) expert practice. These behaviors were discovered through an in-depth process consisting of exhaustive literature review, multiple expert interviews, focus groups, and practitioner-researcher refinement steps. The research design and methodology employed in the identification and characterization of these behaviors, as well as the behaviors themselves, are reported in detail elsewhere. ${ }^{6}$ Using these important CT practice behaviors as the basis of inquiry, survey data were then collected from a national sample of expert medical laboratory scientists, fitting pre-determined study criteria for "expert," practicing in a variety of sites and job structures. The survey measured practitioners' beliefs about the importance of critical thinking (CT) behaviors in their own practices. Of the 65 CT behaviors identified, 25 were considered to be very important in the practice of experts. Not surprisingly considering the nature of the science and technology-based profession, among the behaviors considered important are those usually designated as cognitive. But there are also behaviors representative of the behavioral, affective, and situated/contextual learning/knowledge domains as well. Kenimer Leibach concluded that critical thinking is, in fact, a metaprocess that facilitates learning by interlinking the more basic processes associated with different learning orientations: cognitivist, behaviorist, humanist (affective), and situated/contextual learning. Prototype CT behaviors found in each knowledge do- 
Table 1. Prototype CT Behaviors Found in the Cognitivist, Behavioral, Humanist, and Situated/Contextual Learning Domains*.

\begin{tabular}{|c|c|c|}
\hline$\underline{\text { Learning Domain }}^{\dagger}$ & $\%$ of Total & Critical Thinking Behaviors \\
\hline \multirow[t]{8}{*}{ Cognitivist } & $32 \%(8 / 25)$ & Assuring test accuracy, precision, and validity \\
\hline & & Monitoring for errors \\
\hline & & Evaluating specimen integrity \\
\hline & & Evaluating quality control \\
\hline & & Troubleshooting tasks at work \\
\hline & & Interpreting instrument data \\
\hline & & Documenting the performance of instrumentation \\
\hline & & Seeking relevant information before making decisions \\
\hline \multirow[t]{6}{*}{ Behaviorist } & $24 \%(6 / 25)$ & Focusing $\mathrm{n}$ good patient care \\
\hline & & Practicing responsibility in the workplace \\
\hline & & Accepting responsibility for learning new tasks \\
\hline & & Seeking to improve my own practice and professionalism \\
\hline & & Persevering although difficulties are encountered in tasks \\
\hline & & Continuing to change professionally with changes at work \\
\hline \multirow[t]{5}{*}{ Humanist/Affective } & $20 \%(5 / 25)$ & Demonstrating a caring attitude \\
\hline & & Exhibiting maturity at work \\
\hline & & Wanting to do the right thing in situations at work \\
\hline & & Demonstrating accountability in the workplace \\
\hline & & Demonstrating self-discipline in my work \\
\hline \multirow[t]{6}{*}{ Situated/Contextual } & $24 \%(6 / 25)$ & Balancing multiple tasks at work \\
\hline & & Considering consequences of your actions at work \\
\hline & & Setting priorities among planned and unplanned tasks \\
\hline & & Managing my own time at work \\
\hline & & Using experience to make judgments about tasks \\
\hline & & Communicating with coworkers to accomplish tasks \\
\hline
\end{tabular}

* Adapted from Kenimer, 1999, with permission. ${ }^{10 .}$

${ }^{\dagger}$ Cognitivist $=$ Fact-based, recall, and synthesis learning typical of classroom settings ${ }^{14}$

${ }^{\dagger}$ Behaviorist $=$ Conditioning and psychomotor learning ${ }^{15}$

${ }^{\dagger}$ Humanist/Affective $=$ Attitudinal and transformational learning ${ }^{16}$

${ }^{\dagger}$ Situated/Contextual $=$ Shared and activity-based learning typical of internship experiences ${ }^{7,17}$

main are presented in Table 1 . Next, factor analysis was applied to determine if common threads or themes linked some or all the CT behaviors. The 25 most important CT behaviors were reduced to a 7 -factor structure representing constructs underlying the individual, observable CT behaviors. The seven factors are: Reflecting on Tasks, Acting Professionally, Managing Tasks, Reasoning Technologically, Managing Time, Developing Expertise, and Using Experience. Table 2 contains the seven CLS (MLS) practice behavior themes, or constructs, with some of their representative composite CT behaviors. This tabular frame provides a clearer picture of the elements of CLS (MLS) practice considered most impacted by CT. The factors are listed in order of their perceived significance by expert practitioners. ${ }^{10}$ This typology of important CT behaviors (Table 2) resembles closely behaviors identified as important, not only in CT, but in expert practice in other health professions. For instance, Benner connects the development of expertise, or practical knowledge, to meaningful experience in nursing. For expertise to develop from experience, clinical contexts must be examined through theorybased scientific investigations and the "know how" that develops at the interface of theory and practice must be reflected upon and documented. In her work, Benner identified seven domains of nursing practice that are derived from thematic analysis of expert practice behaviors. Development of expertise in each of these domains depends on the accumulation of practical knowledge at the theory-context interface. A cross-walk among the CT practice themes identified by experts in CLS (MLS) and Benner's expert practice domains in nursing demonstrates the commonalities shared by the constructs. These commonalities are summarized in Table 3.

\section{APPLICATIONS OF CT GROUNDED THEORY IN NURSING}

To measure observable CT events associated with the 
Table 2. CLS Expert Practice Themes with Identifying Composite CT Behaviors*

CT Practice Construct

Reasoning Technologically

Acting Professionally

Developing Expertise

Managing Time

Using Experience

Managing Tasks

Reflecting on Tasks $\underline{\text { Representative Composite CT Behaviors }}$

Demonstrating technical capability:

Assuring test accuracy, precision, and validity

Documenting performance of instrumentation

Practicing with professional demeanor:

Caring attitude, fairness, maturity, perseverance

Responsibility, communication, accountability Continuing to develop professionally:

Continuing to change professionally, keep informed

Seeking to improve practice, continue learning

Navigating the practice context/professional environment:

Setting priorities, Dealing with complexity

Maintaining flexibility and self-discipline/direction

Influencing practice with experience:

Placing value on your contributions

Demonstrating confidence, Using judgment

Practicing within shifting circumstances:

Recognizing when you've done all you can

Identifying alternatives, Revising based on feedback

Appraising outcomes of tasks:

Testing out hunches, Analyzing ideas

Using scientific reasoning, Questioning credibility

* Adapted from Kenimer, 1999, with permission. ${ }^{10}$

Table 3. Commonalities Among Expert Practice Behaviors in CLS and Nursing

CLS BehaviorTheme $^{10}$
Reasoning technologically
Acting professionally

journey from novice to expert within each of the seven practice domains, Benner developed five levels of proficiency in the practice of nursing: novice, advanced beginner, competent, proficient, and expert. As novice practitioners move toward expert, progress in development of CT skills in each of the seven practice domains were assessed by the degree of:

1. movement from reliance on abstract principles to the use of past concrete experience as paradigms,

2. change in the learner's perception of the demand (application) situation, in which the situation is seen less and less as a compilation of equally relevant bits, and more and more as a complete whole in which only certain parts are relevant, and

3. passage from detached observer to involved performer. $^{17}$

Behavior (performance) expectations were then defined for each level of proficiency within each practice domain. With this descriptive empirical work, Benner identified a framework for the identification of nursing competencies appearing along the continuum of novice to expert practice. Further, Benner provides us with a model for capturing the intentions, expectations, meanings, and outcomes of expert practice. In her own words, "Expertise in complex human decision making, such as nursing requires, makes the interpretation of clinical situations possible, and the knowledge 


\section{RESEARCH AND REPORTS}

embedded in this clinical expertise is central to the advancement of nursing practice and the development of nursing science" (p. 3). ${ }^{17}$

\section{APPLICATIONS OF CT GROUNDED THEORY IN MLS PRACTICE}

In our estimation, the great significance of Benner's work lies in its acknowledgment and confirmation of the interdependence and interaction of theoretical and practical knowledge in professional practice. Further this work, through well-documented empirical design and thoughtfully analyzed observations, gives us a model for assessing the influence of context and theory on clinical practice in medical laboratory science. It is becoming increasingly clear that competent clinical practice results from "hybrid" knowledge composed of theoretical knowledge modified by context in its largest sense. ${ }^{6}$ Emergent grounded theory can be summarized, then, as: (1) critical thinking is a metaprocess that facilitates learning by interlinking the more basic processes associated with different learning orientations: cognitivist, behaviorist, humanist (affective), and situated/contextual learning, (2) CT behaviors are observable events following from the CT metaprocess, and (3) observations of CT behaviors increase as practice advances from novice to expert.

Given the relationship of CT to expert practice, MLS educators and other professionals interested in the facilitation of expert practice outcomes among practitioners should evaluate and identify instructional strategies that maximize development of observable skills identified with expert practice and its antecedent, CT. To meaningfully demonstrate the harmony of CTexpert practice and learning theory with various instructional strategies, aspects of CT and optimal teaching strategies for each will be considered.

\section{Instructional Strategies Supporting Expert Practice Development}

In Paul's definition of CT, the cognitive learning orien- tation is represented through the actions of conceptualizing, applying, analyzing, synthesizing, and/or evaluating information, while the behavioral orientation is characterized by observation and experience. Attitudes in the affective orientation are observable elements of the CT process such as reflection, reason, and clarity. Interpersonal events such as communication belong to the situated/contextual learning orientation. Viewing this defining list of observable CT events, or CT skills, e.g., applying, analyzing, etc., through the lens of Bloom's taxonomy emphasizes its association with expert practice. All CT events would be categorized within the higher-order levels of the hierarchy, that is, they would be situated within the categories of application, analysis, synthesis, and evaluation vis-à-vis the less complex levels of knowledge and comprehension. ${ }^{18}$

Having then defined critical thinking and its relationship to expert practice, considerations turn to evaluating the relative merits of instructional strategies that might be employed to teach these CT skills. Table 4 summarizes the relationship of common instructional strategies to CT behaviors and Bloom's learning complexity categories. ${ }^{18,19,20}$

Instructional strategies that would best facilitate learning of more higher-order (more complex) thinking skills are group learning, to include small group and independent study, and mastery learning, i.e., an individualized, self-paced yet group-oriented configuration. Therefore given this scheme for organization of instructional strategies around CT skills development, the instructional strategy representing the best "goodness of fit" is problem-based learning (PBL).

This instructional strategy, first articulated at the end of the last century, is a small group organization allowing for group and mastery learning as well as learner selfdirection. These teaching strategy attributes contribute to long term memory concept integration of CT skills,

Table 4. The Relationship of Common Instructional Strategies to Critical Thinking Skills and Bloom's Learning Complexity Categories

\begin{tabular}{lll}
\hline Instructional Strategy ${ }^{19,20}$ & Bloom's Learning Complexity Level ${ }^{18}$ & Critical Thinking Skill $^{9}$ \\
Lecture/Discussion & Knowledge & None \\
Creativity/Discovery & Comprehension & None \\
Group Learning & Application/Analysis & Applying/Analyzing \\
Mastery Learning & Synthesis/Evaluation & Synthesizing/Evaluating \\
\hline
\end{tabular}




\section{RESEARCH AND REPORTS}

by definition involving learning in multiple orientations, and are, therefore, ideally suited to the education of the healthcare professions. In fact, it can be argued that the traditional "medical model" of education employed in the internship experiences of most healthcare professions is an application of the problembased learning strategy.

\section{DISCUSSION}

In medical (clinical) laboratory science, the need for expert clinical practice, based on higher-order CT skills focused on systems-level outcomes like diagnostic algorithms, care paths, and nationally-monitored quality indicators, has been recognized by the Profession and articulated by the American Society for Clinical Laboratory Science to be at the doctoral level, the doctorate in clinical (medical) laboratory science, DCLS or DMLS. ${ }^{4}$ The need for this new practice has arisen from quality improvement requirements to assess, evaluate, and optimize the impact of laboratory information in medical decision-making and patient outcomes. Traditionally, MLS practice focused on analytics and the provision of quality laboratory information relative to accuracy, precision, sensitivity, specificity, and predictive value. Now measures of quality also include pre-analytic and post-analytic parameters like the appropriateness of medical orders and the effectiveness of utilization of laboratory information. ${ }^{3,21,22}$

Given the prerequisite knowledge requirements of CT and expert practice, this new DMLS practice will be based on the traditional baccalaureate-level MLS scope of knowledge. This baccalaureate foundation will provide the scaffolding for integration of the higherorder thinking processes from which the desired expert practice will emerge. And it is envisioned that a PBL instructional environment during an extensive internship experience will be most effective in facilitating the integration of CT constructs with observable, measurable expert practice outcomes.

Further it is envisioned that the practice of this new DMLS health care professional will embrace the clinical research agenda for evaluation of the medical effectiveness and cost efficiency of laboratory services. Moving toward implementation of the doctorate, MLS clinical and educational researchers alike should implement strategies to teach the CT skills required for this level of practice. Educators in all MLS subdisciplines should work to identify CT practice behaviors, i.e., competencies, along the continuum from novice to expert in the seven MLS practice domains (Tables 2 and 3) and build curriculum supporting their development at each level of practice. Clinical researchers should focus on the development of prototype research methods for the conduct of quality improvement studies that can be modeled by doctoral and post-doctoral laboratory professionals. In these ways and through this work, laboratory professionals will be prepared, not only for PBL internships, but for clinical practice after program completion.

Identification and definition of CT behaviors, i.e., practice competencies, along the continuum of novice to expert can serve as the foundation for MLS curriculum and instructional design as well as measurement and evaluation in not only formal but continuing education settings, as well. As advancing MLS practice requires more and more CT practice behaviors in the social/contextual orientation, e.g., inter-professional communication related to nonanalytic practice questions and data collection, the expert practice development theory portends a framework for research to discover and teach to the development of these requisite skills for currently practicing, as well as novice, MLS.

The medical laboratory science profession would do well to internalize, adapt to MLS, and act on the words of Benner regarding the value of critical thinking and expert practice in nursing, "...the knowledge embedded in this clinical expertise is central to the advancement of [MLS] practice and the development of [MLS] science." 17

\section{REFERENCES}

1. Chantrill C. US Government Spending.com. Available from http://www.usgovernmentspending.com/. Accessed 2011, August 20

2. Rampell C. U.S. Health Spending Breaks From the Pack. New York Times; Saturday, March 27, 2010. Available from http://economix.blogs.nytimes.com/2009/07/08/us-healthspending-breaks-from-the-pack/. Accessed 2011, August 20.

3. Laposata M, Dighe AS. "Pre-pre" and "post-post" analytical error: High incidence patient safety hazards involving the clinical laboratory. Clin Chem Lab Med 2007;45:712-9.

4. Leibach EK. The Doctorate in Clinical Laboratory Science: A view of clinical practice development. Clin Lab Sci 2008;21(4):196-8. 


\section{RESEARCH AND REPORTS}

5. Ranne $\mathrm{AB}$. The roles of the clinical laboratory scientist: educator, consultant, advocate. Clin Lab Sci 2009;24(4):196202.

6. Kenimer EA. The identification and description of critical thinking behaviors in the practice of clinical laboratory science, part 1: Design, implementation, and evaluation of a national survey. J Allied Health 2002;31(2):56-63.

7. Schon DA. The reflective practitioner. USA: Harper Collins (Basic Books); 1983

8. Resnick LB, Klopfer LE. Toward the thinking curriculum: An overview. In LB Resnick \& LEKlopfer (Eds.). Association for curriculum and supervision development yearbook. University of Pittsburgh: Learning Research and Development Center Press; 1989.

9. Paul RW. Critical Thinking Handbook: Basic Theory and Instructional Structures. Santa Rosa, CA: Foundation for Critical Thinking, 2000.

10. Kenimer EA. The identification and description of critical thinking behaviors important to clinical laboratory science (Doctoral dissertation), The University of Georgia. Dissertation Abstracts International, 60-05, A1420;1999.

11. Leibach EK, Russell BL. A typology of evidence based practice research heuristics for clinical laboratory science curricula. Clin Lab Sci 2010;23(3)Suppl:46-51.

12. Glaser BG. A look at grounded theory: 1984-1994. Grounded theory 1984-1994, Vol. 1. Mill Valley, CA.: Sociology Press. 1995.
13. Bacharach SB. Organizational theories: Some criteria for evaluation. The Academy of Management Review 1989;14(4):496-515.

14. Piaget J. Psychology of intelligence. Totowa, NJ: Littlefield, Adams; 1966.

15. Skinner BF. About behaviorism. New York: Knopf; 1971.

16. Maslow AH. Motivation and personality. 2nd Ed. New York: Harper \& Row; 1970.

17. Benner P. From novice to expert: Excellence and power in nursing practice. Menlo Park: Addison-Wesley; 1984.

18. Bloom BS, Krathwohl DR. Taxonomy of educational objectives: The classification of educational goals, by a committee of college and university examiners. Handbook 1: Cognitive domain. New York: Longmans. 1956.

19. Timpson WM, Bendel-Simso P. Concepts and Choices for Teaching: Meeting the Challenges in Higher Education. Madison, WI: Magna Publications, Inc. 1996.

20. Research Digest: Effective Instructional Strategies. Edvantia. Available from http://www.edvantia.org/pdta/pdf/Effective_ Instructional_Strategies.pdf. Accessed 2011, August 20.

21. Otto CN. Patient safety and the medical laboratory: Using the IOM aims. Clin Lab Sci 2011;24(2):108-13.

22. Otto CN. Patient Safety and the medical laboratory: An introduction. Clin Lab Sci 2011;24(2)105-7.

The findings and conclusions in this presentation are those of the author(s) and do not necessarily represent the official position of the Centers for Disease Control and Prevention.

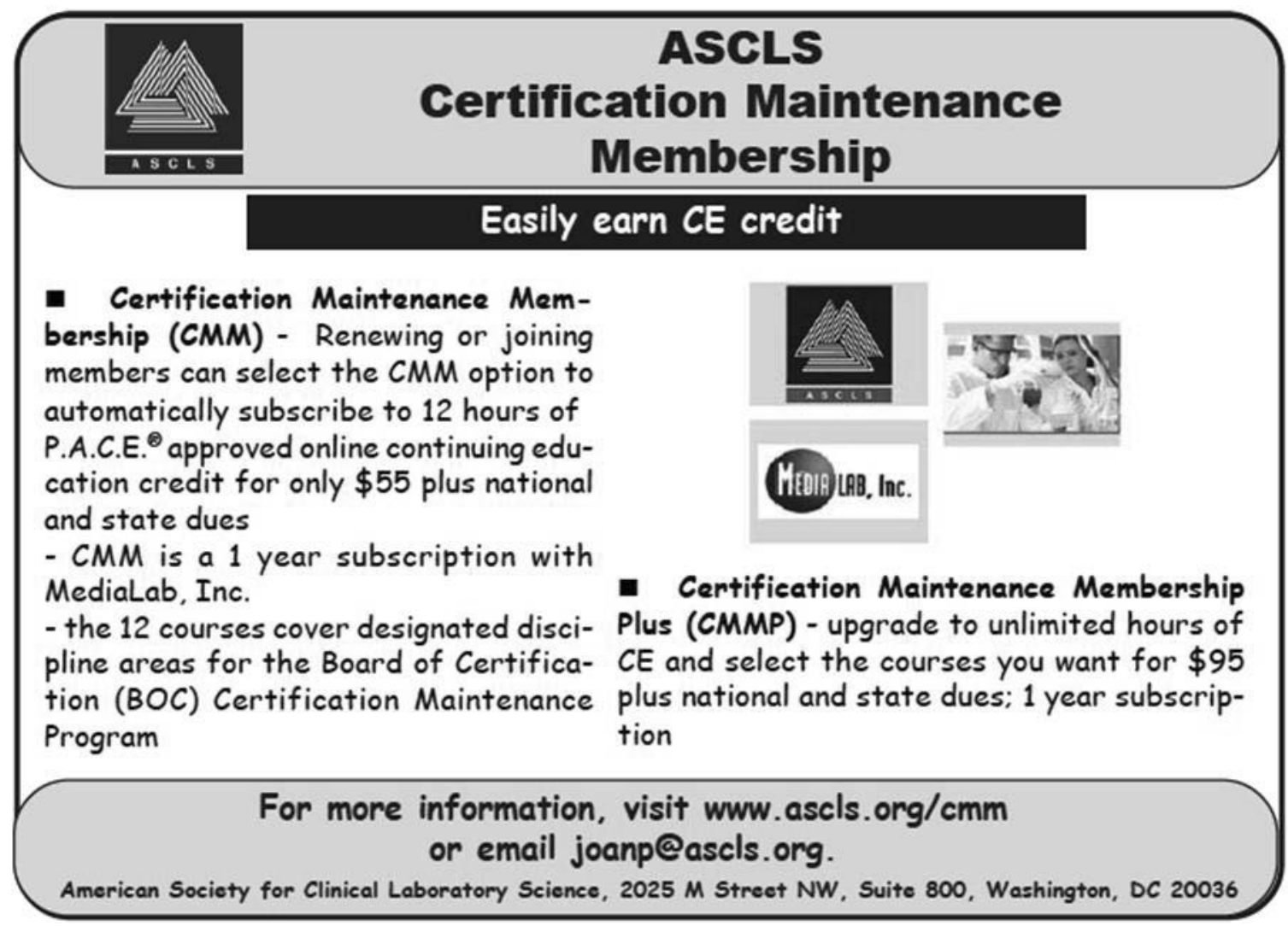

